\title{
The risk to reconstitution: supply chain risk management for the future of the US Air Force's organic supply chain
}

\author{
David Loska and James Higa \\ US Air Force, Tinker AFB, Oklahoma City, Oklahoma, USA
}

\begin{abstract}
Purpose - The future retirement of US Air Force (USAF) legacy weapon systems (WSs) removes their associated funding from within the Air Force Working Capital Fund and their parts from its organic supply chain inventory. The trending outsourcing of product support to contracted logistics support and its potential long-term consequences to the USAF government-owned, government-operated, organic supply chain and the reconstitution capabilities it enables in the USAF's organic industrial base, suggests the need to assess its risks. Although there is an existing body of research into the risks of outsourcing the USAF's industrial repair, and federal legislation such as Core 50/50 laws enacted to institutionalize its risk management, there is comparatively little research into the outsourcing risks to the long-term viability of the supply chain on which that repair capability is dependent. The aim of this research is to fill that research gap by assessing and modeling those risks. This research concludes by providing several future research directions that may be evaluated to provide more detail.
\end{abstract}

Design/methodology/approach - Leveraging a conceptual model derived from research and a multicriteria analysis framework to assess supply chain risk. Quantifying the predicted impact of retirements on funding and inventories of unique parts. Modeling the potential risk due to WS retirement.

Findings - Results indicated long term enterprise risks to the Air Force's supply chain correlated to the retirement of WSs and their associated funding and spare parts inventory.

Originality/value - This research provides an in-depth evaluation of the USAF's supply chain to assess the holistic risk of product support outsourcing and its long-term impacts on viability by using resourcebased view and contingency theory as theoretical underpinnings. In addition, insights and implications for defense supply chain managers and decision-makers.

Keywords Outsourcing, Purchasing, Supply chain risk management, Risk and vulnerability, Acquisition and procurement, Air force

Paper type Research paper

\section{Introduction}

The future retirement of US Air Force (USAF) legacy weapon systems (WSs) such as the A-10 and KC-135 removes their associated funding from within the Air Force Working Capital Fund (AFWCF) and their parts from its government-owned, government-operated, organic supply chain inventory, impacting the fleet reconstitution capabilities and resilience it enables in the USAF's defense industrial repair base. In Figure 1, product support outsourcing decisions made between 1990 and 2015 imply that funding for aircraft procured

(C) In accordance with section 105 of the US Copyright Act, this work has been produced by a US government employee and shall be considered a public domain work, as copyright protection is not available. Published in Journal of Defense Analytics and Logistics. Published by Emerald Publishing Limited.
Supply chain risk management

Received 5 March 2019

Revised 14 July 2019 31 July 2019

13 December 2019

5 March 2020

11 March 2020

Accepted 12 March 2020 
$\underset{4,1}{\mathrm{JDAL}}$

20
Figure 1.

SCM provider by initial operational capability (IOC) decade by WS during that period will not replace the retired funds. The impact of this is uncertain and potentially contributes to the vulnerability of the USAF's supply chain. This uncertainty leaves the USAF unable to "develop a probabilistic estimate or list all possible alternative outcomes related to a decision or an event” (Manuj and Mentzer, 2008).

The 448th Supply Chain Management Wing (448 SCMW), located at Tinker AFB, OK, leads the USAF's wholesale supply chain management (SCM). The 448 SCMW manages a 115,000-item portfolio of depot-level repairable (DLR) spare parts with an inventory valued at $\$ 51.9 \mathrm{bn}$. The 448 SCMW runs the planning and management of this portfolio through a $\$ 6.8 \mathrm{bn}$ annual budget authority within the AFWCF within the consolidated sustainment activity group's supply division (CSAG-S).

Working within the AFWCF, the CSAG-S is primarily responsible for the management of the USAF'S DLRs and USAF managed consumable parts. The AFWCF is a "revolving fund," balanced year to year, breaking even and neither generating a profit nor sustaining a loss over the long term. This fund returns revenue or recovers losses through cash adjustments the following year. Customers in this artificial economic construct "buyerseller" approach to the Department of Defense (DoD) financial management will use appropriated funds to finance orders from providers, such as the 448 SCMW. These providers set costs based on the previous account balance and current year management at a single overhead rate surcharge called the business overhead cost recovery (BOCR) (AFSC, 2018). Financial managers calculate the BOCR by dividing the overhead expenses and adjustments by buy and repair expenses. The resulting surcharge rate is a standard applied across price calculations for all exchangeable items.

During the years 1990-2015, the USAF showed a preference toward contracted logistics support (CLS) for outsourced and privatized product support of SCM functions for new WSs. Figure 2 shows that this period introduced only $3 \%$ of the USAF's total buy and repair budget for new WSs.

Current organically supported legacy WSs introduced between 1950 and 1980 represent the preponderance of CSAG-S funding. This means the USAF's organic supply chain is mainly in the "legacy parts business" (Washburn, 2016). CLS supported WSs can show increased performance in SCM metrics such as "total not mission capable supply" (TNMCS); however, research concludes that this depends predominately on funding and many other factors such as the age of WS, finding "it could be simply that programs with better TNMCS have received better funding (Botio et al., 2009).”

The potential for WS retirement coupled with product support outsourcing decisions could draw resources from the USAF's organic supply chain, thereby challenging its future viability and resiliency. Outsourcing decisions for product support are made at the respective WS program offices, decentralized from the wholesale purchasing function of the supply chain (GAO, 2017). "Program offices sometimes make decisions that are in the best interest of the program but not in the best interest of the Air Force as a whole" (Botio et al., 2009). Decentralized supply chain outsourcing is not unique to the military. According to a study (Dittmann, 2014), which surveyed 150 supply chain executives and conducted

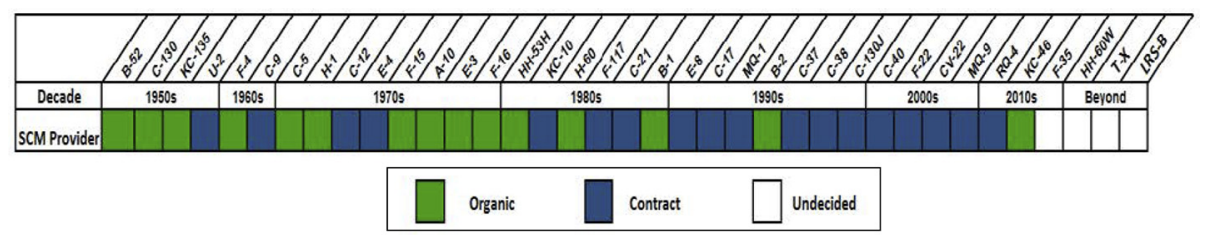




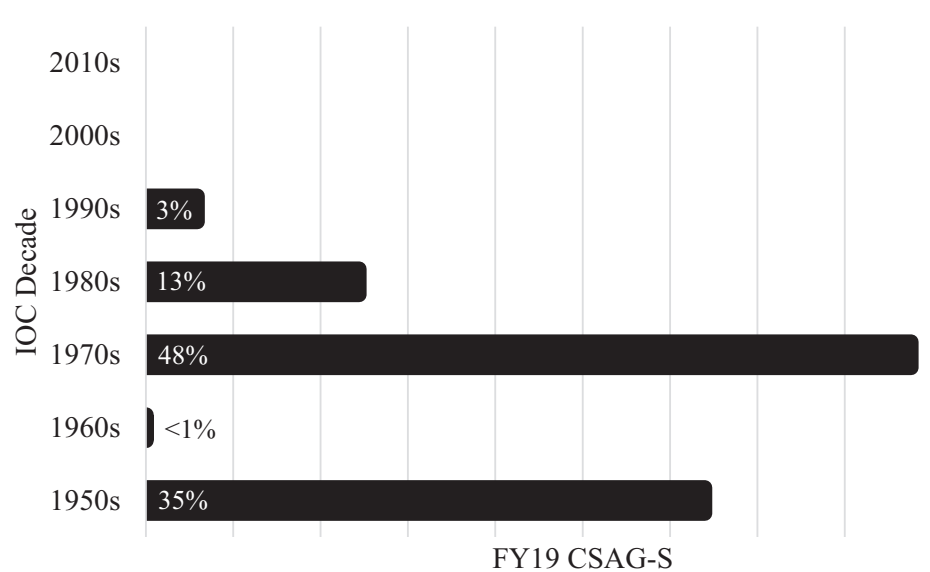

Supply chain risk management

Figure 2.

FY19 CSAG-S by WS IOC decade

interviews with executives from six companies, "ninety per cent of the firms surveyed do not measure supply chain risk when outsourcing production and none use outside expertise to help assess supply chain risks." Some program offices have recently chosen organic supply chain support for WS sustainment over CLS, the effects of which have not yet been realized. Understanding downstream risk is necessary for driving sound upstream decisions. The US DoD uses legally mandated reporting procedures for risk management of the outsourcing of its industrial depot repair, and federal legislation such as Core 50/50 laws (10 U.S.C. 2464, 2466) to institutionalize its risk management. No such process exists for the USAF's supply chain. However, the organic supply chain is responsible for managing the USAF's DLR spares upon which its industrial repair and reconstitution capabilities are codependent.

The focus of this paper is a framework for assessing the long-term enterprise risks to the USAF's supply chain due to the retirement of WSs leading to the loss of their associated funding and spare parts inventory. The methods used include the solicitation of unstructured feedback from both wholesale and retail supply chain managers, construction of a framework based on a resource-based view (RBV) and consideration of realistic timelines for the retirement of existing weapons systems. These methods help to:

- estimate the future impact of retirements on funding and inventories of unique parts; and

- model the potential long-term risk due to WS retirement in an era of outsourcing product support.

\section{Literature review}

The literature review addresses the key areas directly related to the research, establishing definitions for supply chain risk, resilience and vulnerability. The review also surveys key research on supply chain risk management, outsourcing and the purchasing and procurement functions of a supply chain.

Key concepts

We define risk and risk management of the USAF's wholesale purchasing supply chain of the 448 SCMW, hereafter referred to as the organic supply chain, and its outsourcing using 
$\mathrm{JDAL}_{4,1}$

22

various sources and frameworks. The project management institute (PMI, 2018) defines risk as "an uncertain event or condition that, if it occurs, has a positive or negative effect on one or more project objectives." Similarly, the DoD (2017) defines defense acquisition programmatic risk as "potential future events or conditions that may have a negative effect on achieving program objectives for cost, schedule, and performance." An enterprise approach to risk management is offered by the Committee of Sponsoring Organizations of the Treadway Commission (COSO, 2004). Upholding:

Enterprise risk management is a process, effected by an entity's board of directors, management and other personnel, applied in strategy setting and across the enterprise, designed to identify potential events that may affect the entity, and manage risk to be within its risk appetite, to provide reasonable assurance regarding the achievement of entity objectives.

Commonly, researchers and authoritative organizations prescribe multistep process frameworks for risk management (COSO, 2004; Manuj and Mentzer, 2008; DoD, 2017; PMI, 2018). These frameworks hold that early and accurate risk identification and assessment can enable better management of risk, increasing an organization's resilience to recover from or avoid a disturbance or minimize the propagation of an event.

Many strongly relate definitions of risk to the probability of the occurrence of disruptive events (Craighead et al., 2007). The assessment of supply chain risk is also closely related to the concept of vulnerability and to the objectives of the underlying supply chain. According to Heckmann et al. (2015), the degree of achievement of these objectives depends on the exposition of the underlying supply chain toward unexpected and uncertain developments. This exposition is described by concepts such as vulnerability, i.e. "the extent to which a supply chain is susceptible to a specific or unspecific risk event" and resilience, i.e. "a supply chain's ability to return to its original or move to a new, more desirable state after being disturbed." Heckmann et al. further support that time-aspects must be considered when referring to disruptive triggers and the preparedness of the affected supply chain (Heckmann et al., 2015).

One can measure risk in a variety of ways. Aven (2008) classifies risk analysis methods into categories of simplified risk analysis, using qualitative measures and no formal methods, standard risk analysis where both qualitative and quantitative methods are used with tools such as hazard and operability analysis and coarse risk analysis, and model-based risk analysis, primarily quantitative with tools such as event tree analysis and fault tree analysis. Heckmann et al. (2015) offer that risk assessment literature focuses on approaches that are mathematical, conceptual and empirical. The authors categorize risk assessment modeling approaches into downside risk approaches (such as value-at-risk and conditional-value-atrisk), deviation approaches, approaches that do not quantify the degree of risk related to a solution, which is described as not further quantified, those approaches that asses probability and those the authors categorize as other. Supply chain risk management literature also suggests hierarchy structuring approaches or value hierarchy methods for supply chain decision-making, methods such as simple multiattribute rating theory, for source selection or outsourcing decisions (Olson, 2012). Multi-objective or multi-criteria analysis approaches can be used to evaluate different types of supply chain objectives such as complex problems that are characterized by a mixture of monetary and non-monetary objectives and factors in environments with possible uncertainty. Multi-criteria analysis can be used either retrospectively to evaluate things to which resources have already been allocated or prospectively to appraise things that are as yet only proposed. These related techniques have been applied in various ways to supply chain risk management (Loredo et al., 2015; El Khayyam and Herrou, 2016; Moktadir et al., 2018) and supply chain decision-making 
(Barker, 2011; Borade et al., 2013; Da Cruz et al., 2013; Khan, 2018; Wang et al., 2018). In this work, to calculate organic supply chain risk (Figures 11 and 12), a technique similar to that of Loredo et al. (2015) is used to determine supply chain risk, wherein Loredo et al. (2015) assessed the multiple-criteria of parts in the US Army supply inventory and applied the time-aspect of days until item stock-out.

Supply chain risk management research by Manuj and Mentzer (2008) holds that "to manage global supply chain risk, companies need to follow a path from risk identification to strategies to deal with risks." Kouvelis and Milner (2002) posit, "greater supply uncertainty increases the need for vertical integration while greater demand uncertainty increases the reliance on outsourcing." It was during a time of demand uncertainty that in 1948, while amidst a budget and workforce constrained environment, a very sudden increase in flying and maintenance workload brought about by Operation Vittles and the Berlin Airlift, the USAF first began to outsource its industrial repair. Within 10 years, the USAF's contract maintenance portfolio grew from a proportionately small $7 \%$ in fiscal year (FY) 48 , to $56 \%$ of the total USAF workload by FY58 (Stierlitz, 1974).

Organizations outsource workloads and functions to achieve a variety of benefits, including becoming more efficient or responsive. Outsourcing supply chain functions such as to a third-party logistics provider can reduce current and future costs, improve customer satisfaction, provide global expertise, reduce risk and enable startup operations (Dittman and Vitasek, 2016). Hätönen and Eriksson (2009), summarize and predict the development and future outlook for outsourcing, suggesting that outsourcing will continue to be a permanent part of the business landscape.

According to a study conducted by the RAND Corporation's Project Air Force:

Two major commercial trends that $\mathrm{DoD}$ and the Air Force have been adopting - inventory reductions and outsourcing - can make supply chains more productive but also riskier (Moore et al., 2015).

Outsourcing can also lead to short term organizational competitiveness but "contributes little to building the people-embodied skills that are needed to sustain product leadership (Prahalad and Hamal, 1990)," and yields more through "outsourcing for longer-term knowledge-based system or strategic benefits, like greater intellectual depth and access, opportunity scanning, innovation, reliability, quality, value-added solutions, or worldwide outreach (Quinn, 1999).” In response to changing industry dynamics, aerospace firms may choose to insource those services previously outsourced. According to a survey of aviation maintenance, repair and overhaul (MRO) leaders (including $>125$ aviation professionals from airline operators, captive airline MROs, independent MROs and original equipment manufacturers $(\mathrm{OEMs}) \cong 50 \%$ senior executives; $\cong 80 \%$ director level or above) published by management consulting firm Oliver Wyman (Prentice and Costanza, 2019), 65\% of respondents find it highly likely and $24 \%$ find it likely that "airframe OEMs will develop more capabilities (internally or through joint ventures). Respondents to this survey also identified that "consolidation within distributors" was 35\% highly likely and 47\% likely in their organizations. Furthermore, that "airframe OEMs will develop more capabilities through Tier $1 / 2$ OEM acquisitions," respondents found $37 \%$ highly likely and $42 \%$ likely.

The USAF is evaluating insourcing its WS sustainment and looking to shift the industry into development, and away from sustainment, which consists of $70 \%$ of the USAF's total life-cycle spending (Tribble, 2019). The work of Hartman (2013) suggests that this "outsourcing-to-insourcing relocation shift" is part of an oscillating cycle within the USAF. This oscillation was described by Fine (2000), who considers the cycles a response to: 
$\underset{4,1}{\mathrm{JDAL}}$

Forces at work within both horizontally and vertically integrated industries which create pressure for the industry to evaluate its supply chain design - vertically integrated supply chains face internal and external pressures to become more horizontal or disintegrated and horizontally integrated supply chains are pushed toward vertical integration to relocate supply chain structures disintegrated side to integrated side.

Wholesale supply management, purchasing and procurement are inseparable factors in SCM (Kraljic, 1983) and contribute to resilience in light of risk (Da Silva et al., 2016). Therefore, the design of the wholesale purchasing functions within a supply chain is impacted by disruptions and contributes to the overall resilience of a supply chain structure.

Although there is a body of research and government studies on the risks of outsourcing the USAF's industrial repair, and legislation such as Core 50/50 laws enacted to institutionalize its risk management, there is surprisingly little research assessing the risk of the long-term viability of the USAF's organic supply chain on which its industrial repair capability is dependent. Fundamentally, "holistic sources of risk signify that an overall analysis of the supply chain is required in order to assess risk (Manuj and Mentzer, 2008)." These sources of risk and vulnerability suggest the need to assess the USAF's overall supply chain risk with an appropriate framework. Such a framework should evaluate both the composition of the organization's resources and its alignment with the USAF's organizational objectives, strategy and processes.

\section{Theory}

\section{Resource-based view}

The RBV provides a framework explaining that resources when strategically managed and combined, create unique capabilities and increase performance within a firm or organization (Wernerfelt, 1984; Barney, 1991). However, a resource is independently insufficient to create unique capabilities (Barney, 1991). RBV Theory has been used by researchers to identify motives for outsourcing (Hätönen and Eriksson, 2009), as a theoretical base for supply chain research (Mentzer et al., 2004; Esper et al., 2007; Byrd et al., 2008), to show how knowledge development capacity and intellectual capital enhance supply chain performance (Craighead et al., 2009) and to develop a risk management framework to assess supply chain risk and resilience (Blackhurst et al., 2011; Mandal, 2012).

The theoretical foundations of the RBV describe three categories of resources that may be used to create capabilities. These resources are categorized by Barney (1991) as, "physical capital resources (Williamson, 1975), human capital resources (Becker, 1964), and organizational capital resources (Tomer, 1987).” Within this framework:

Physical capital resources include the physical technology used in a firm, a firm's plant and equipment, its geographic location, and its access to raw materials. Human capital resources include the training, experience, judgment, intelligence, relationships, and insight of individual managers and workers in a firm. Organizational capital resources include a firm's formal reporting structure, it's formal and informal planning, controlling, and coordinating systems, as well as informal relations among groups within a firm and between a firm and those in its environment.

The organizational composition of the USAF's supply chain resources must be assessed beside its organizational objectives, strategy and processes to evaluate the holistic risk to outsourcing decisions and their long-term impact on supply chain viability. Understanding the downstream risks to WS sustainment and reconstitution capabilities is necessary to driving sound upstream decisions within WS acquisition. 


\section{Contingency theory}

Contingency theory (Lawrence and Lorsch, 1967; Donaldson, 2001) addresses variations in the environment or an open system in terms of stability and certainty within an organization and how it corresponds with differences in the internal structuring. This implies that there is no one correct way to organize, but that a firm should be adaptative. Further, any structuring is contingent upon events and circumstances. It has been used as a theoretical base for research into the supply chain integration between a manufacturer and its supply chain (Flynn et al., 2010) and research into the impact of the USAF's strategic alignment of inventory practices on its overall resilience and continuity (Boone et al., 2013). Lawrence and Lorsch's (1967) foundational research assessed the subunits of the organizations within their study (e.g. manufacturing, sales, research and development) and found that there was a positive relationship in performance between those organizations that were both highly differentiated and well-integrated with their subunits. The theory informs and reinforces the USAF's decisions to either insource workload and functions (Hartman, 2013) or outsource product support to CLS for gains in the cost, schedule and performance within the program office (Botio et al., 2009). Contingency theory holds that the most effective organizational structural design is one where the "structure fits the contingencies (Donaldson, 2001)."

\section{Data and methodology}

This study assesses the holistic risk to the USAF's organic supply chain to the outsourcing of product support and its long-term impacts on viability as WSs are retired.

During the data collection and design phase, unstructured feedback was solicited from USAF wholesale and retail mid to high-level managers at four geographically distributed USAF bases under the working group organization of the supply chain execution group (SCEG), and conferred accuracy through four teleconferences. Feedback from the SCEG on the concerns and effects of outsourcing product support (synthesized in Figure 3), was varied by organization and position; however, it revealed consistent themes. This data helps

\section{Future Workloads}

- Cost to Logistics Reassignment

- Opportunity cost to competitiveness by not maintaining modern processes/skillsets

\section{Funding Consistency}

- Risk in a fiscally constrained environment to shifting funding away from organically supported weapon systems as CLS funding is committed

\section{Intellectual Capital}

- Maintaining the in-house core competencies necessary to make informed outsourcing decisions

- Knowledge, processes, skills, expertise

\section{Impact to Overhead}

- Reduction in CSAG-S funding increases overhead BOCR surcharge, increasing cost to other Program Offices and reducing competitiveness under Product Support Business Case Analysis (PS-BCA)

Figure 3.

SCEG feedback on concerns and effects of outsourcing product support 
$\underset{4,1}{\mathrm{JDAL}}$

explain the "how" and "why" effects of outsourcing and influenced the criteria for the RBV factors choices.

The most consistent theme found was a concern to future workloads. With the organic supply chain being primarily in the "legacy parts business," there is a concern that skills and processes will atrophy as legacy WSs are disposed of and, without modern WS workload to replace them, will result in an opportunity cost to competitiveness and viability. Further, there were concerns over the cost of "logistics reassignment." This term is used to describe an event that a WS previously supported through CLS is inducted into the organic supply chain. This event may occur due to a lack of profitability or interest on the part of the OEM or CLS provider or for some other reason. OEMs and CLS providers must also maintain viability and competitiveness. Pooling resources to support older technology through sustainment phases of a WS can come at an opportunity cost to developing more modern skillsets and processes for long-term profitability. This event can transpire into diminishing manufacturing sources and material shortages and obsolescence issues within the organic supply chain and sole source no-bid contracting scenarios. A phrase that was consistently repeated between mid to high-level wholesale managers was "eventually, everything becomes organic," for which some expressed concern that the USAF was unprepared.

Extending RBV theory to measuring risk and apply those factors longitudinally over the time of WS retirement dates, meant choosing the most relevant and straightforward factors that could be triangulated (Jick, 1979) and assigned to a specific WS, representing each of the RBV categories. Because impact and consequence of an event (PMI, 2018) can be assigned to dependence on a particular factor (DoD, 2017), factors need to form a clear relational inference (Meridith, 1998) between RBV factors and the retirement of weapons systems. This logic supports the internal validity of the study (Yin, 1994). These factors are CSAG-S funds by WS as referenced on the SM-3B schedule of the FY19 AFWCF (SAF/FM, 2018) measured by per cent of the total assigned by WS, and unique parts by item number or National Stock Number (AFSC, 2019b) of the total parts portfolio. Within RBV theory, resource categories interact among and between themselves to enhance, reduce and represent supply resilience (Blackhurst et al., 2011). It may be intuitive that funding and parts can be attributed to a WS and the organic supply chain's physical capital resources under RBV, but it is not immediately apparent how those factors together represent each of the RBV categories and interact between each other. This relation is due to the alignment of people and processes of the organic supply chain under the integrated product and process development organizational model and the design and use of integrated product teams (IPTs) for product support execution (DoD, 1998). For example, a logistics management specialist is generally responsible for:

Identifying the specific requirements for money, manpower, materiel, facilities, and services needed to support the program; and correlating those requirements with program plans to assure that the needed support is provided at the right time and place (USAF, 2019).

IPTs have been used as a framework to assess supply chain relationships (Humphries, 2003); as such, their core competencies can be assigned to "core parts" (Prahalad and Hamal, 1990). Thus, CSAG-S funds and unique parts in addition to representing physical capital resources, create relational inference and a logical bridge aligning the human capital resources and the organizational capital resources of the people, processes, systems, tools and resources used in the organic supply chain as outlined on the framework in Figure 4.

Equal weight was assigned to $C S A G-S$ funds and unique parts factors because each factor, mutually independent of the other, does not accurately represent holistic dependence. 
For instance, a relatively small portfolio of parts on a technologically advanced or expensive WS might account for a disproportionate amount of funds as compared to a more extensive portfolio of parts of a less complex or costly WS. Because it would be challenging, if not impossible to measure the complexity of the interactions between all factors and capture all the interactions in one broad study (Blackhurst et al., 2011), this study limited factors to only those with a clear relational inference (Meridith, 1998).

The unclassified retirement or disposal date for each WS came from the Air Force Life Cycle Management Center reliability and maintainability information system database managers and the headquarters Air Force (HAF) A8 analysis branches. For the two legacy WSs with unavailable retirement dates, the date was set as the median of the combined weapons system retirement dates. Additionally, CSAG-S funding for aircraft engines is accounted separately from each WS (SAF/FM, 2018) but together in revenue accounting. Therefore, it is assumed that the combined disposal date for propulsion systems corresponded to their associated WS. Applying CSAG-S funds longitudinally over disposal dates involved a simple simulated disposal plan; this was not applied to unique parts. When WSs are retired, they are divested over time. This schedule is based on factors such as new WS procurement rates and the Aerospace Maintenance and Regeneration Group induction schedule. Therefore, a standard 10\% decrease in CSAG-S funding per year was applied for 10 years leading up to the disposal date. This logic was verified with the data source. These determining factors complete the "chain of evidence," supporting construct validity and reliability (Yin, 1994; Ellram, 1996).

\section{Analysis and results}

The retirement of legacy systems, coupled with the potential impact from product support outsourcing decisions from 1990 to 2015 and their associated reduction of RBV factors brings about an uncertainty that has yet to play out. Figure 5 shows the different product support arrangements for the USAF's current WSs and future programs.

CSAG-S funds by WS measured by percent of the total applied longitudinally over retirement dates are shown in Figure 6. A chart line representing current FY19 dollars with a then-year adjustment under USAF raw inflation indices (SAF/FMCE, 2019) is provided for comparison.

Unique parts by item number by percent of the total unique parts portfolio applied longitudinally over retirement dates are shown in Figure 7.

The combined CSAG-S funds and unique parts factors in the RBV risk factors framework applied longitudinally over retirement dates are shown in Figure 8.

Forecasted budget estimates and funding timeline for the $\mathrm{KC}-46$ from the current product support business case analysis and forecasted spares provisioning data obtained from the supply chain planning and execution office of the 448 SCMW are shown in Figure 9. This shows the reliability of this model with the inclusion of new data. Though only estimates at the time of this study, this begins to show that induction of new workload with a long

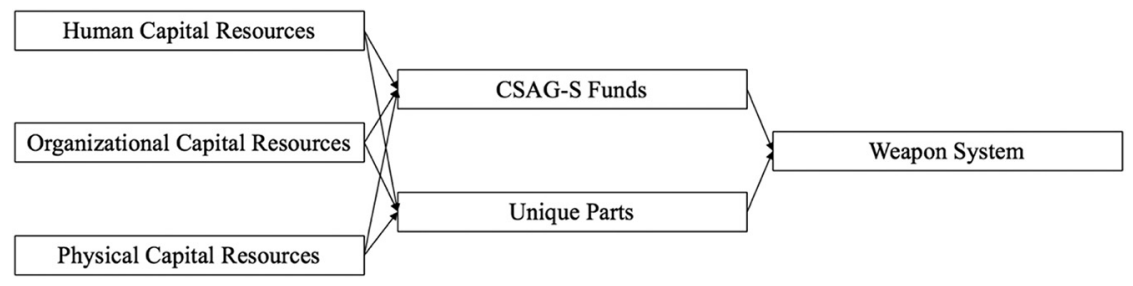

Supply chain risk management

. 
$\mathrm{JDAL}_{4,1}$

28

Figure 5.

Enterprise level review
Figure 6.

CSAG-S funds by WS over retirement 1950s

2020s

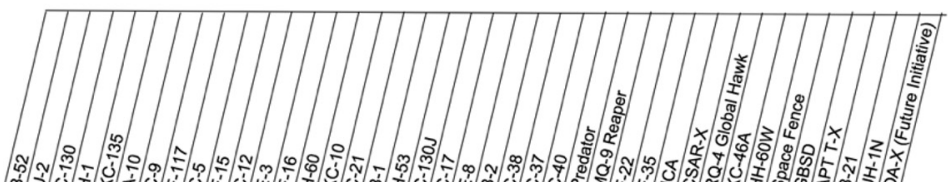

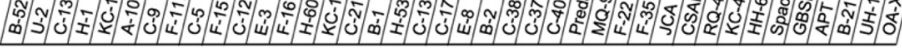
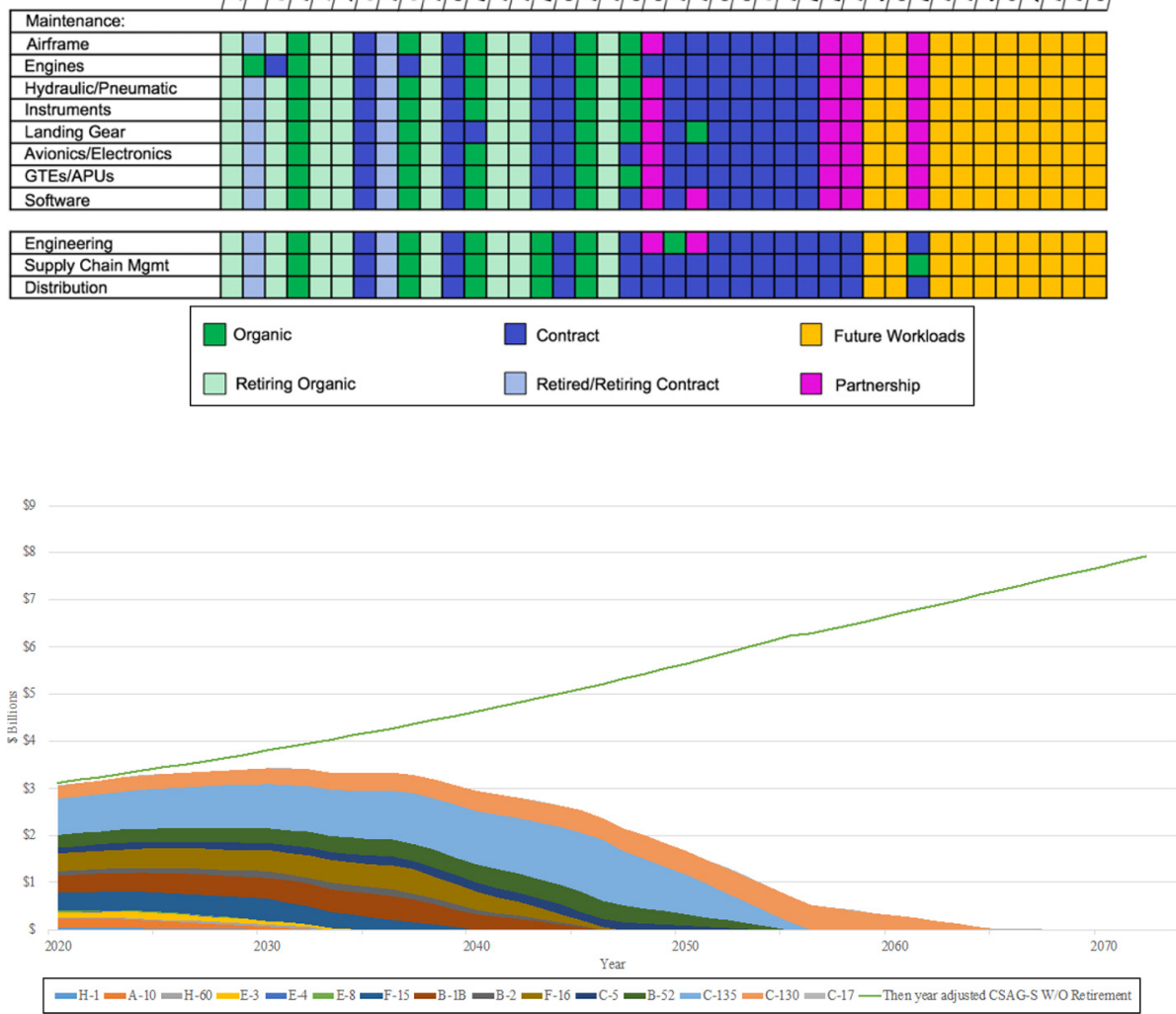

enough lifecycle reduces the dependence of the organic supply chain on any one system. This distributes dependence, thereby reducing vulnerability and increasing resilience.

The results of the analysis yielded four sets of data measuring the negative impact on the organic supply chain by year caused by decreases in the percent of RBV factors within the research framework. There is a negative and inversely proportional relationship between the RBV factors and the USAF organic supply chain. The first two data sets (Table 1) show the impact on the independent RBV factors as percent reductions:

(1) The then-year adjusted financial outlook for the CSAG-S fund's factor; and

(2) The unique parts factor measured by percent of the total inventory portfolio.

The second two data sets (Table 2) show the impact on the overall RBV of the organic supply chain by year with the added new workload from the estimated $\mathrm{KC}-46$ forecasted data. 


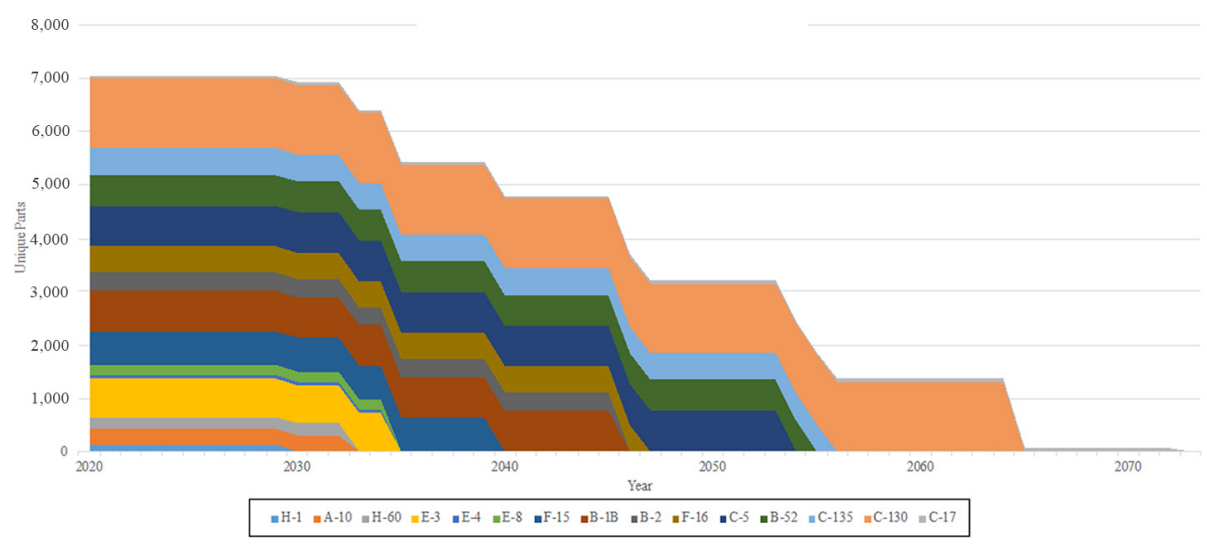

Supply chain risk management

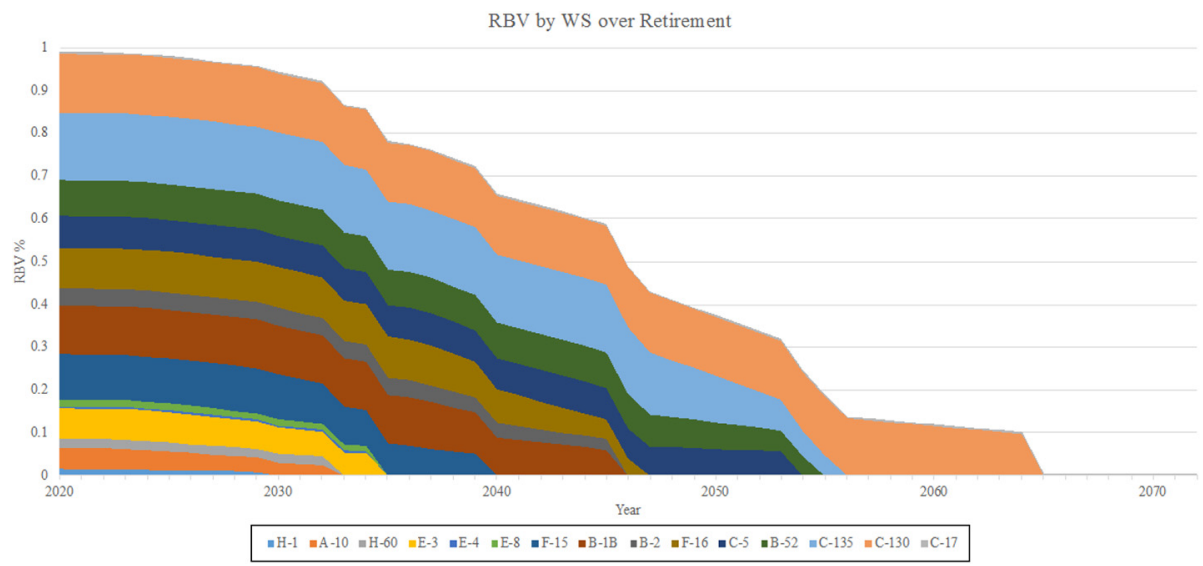

Figure 8. RBV by WS over retirement

The RBV risk factors framework could be applied to a generic risk matrix providing "a standard format for evaluation and reporting of program risk assessment findings," which "facilitates common understanding of program risks at all levels of management" (DoD, 2017). RBV factors could be scaled to represent consequence and impact, and the years to retirement could be scaled to represent likelihood. This matrix could be categorized by WSs, subcategorized by subsystems or broadened by mission type, e.g. fighter, bomber, mobility, etc. (a possible risk matrix is shown in Figure 10).

Another possible means of measuring the same RBV risk factors could involve the development of an enterprise-level organic supply chain risk assessment (a possible representation shown in Figure 11). Although it would be limited in its ability, showing only the average risk, accumulating after WS's disposal, it could be helpful in identifying increasing or decreasing vulnerability through the dependence of the supply chain on RBV factors and assessment with uncertainty and time-aspects of weapons systems disposal. 
JDAL

4,1

30

Figure 9.

RBV by WS over retirement with $\mathrm{KC}$ 46 estimates
RBV by WS over Retirement

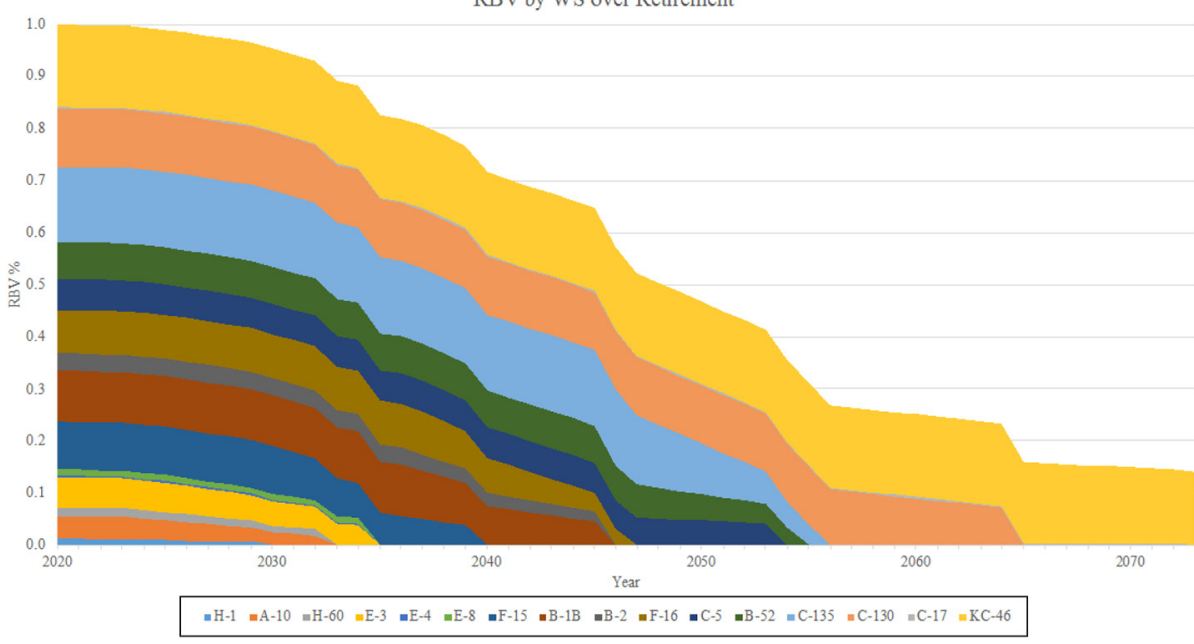

Table 1.

Independent RBV factors impact

\begin{tabular}{lcccc}
\hline RBV factor & $2030(\%)$ & $2040(\%)$ & $2050(\%)$ & $2060(\%)$ \\
\hline CSAG-S funds & -9.6 & -36.5 & -70.4 & -95.4 \\
Unique parts & -1.7 & -31.9 & -54.5 & -80.6 \\
\hline
\end{tabular}

WS risk could be calculated as:

$$
\text { WSRisk }=\frac{1}{2}(\text { Funding Risk }+ \text { Inventory Risk }) *\left(1-\frac{\text { Yrsto Retirement }}{\text { Longest Yrsto Retirement }+1}\right)
$$

Where:

$$
\text { Dependence }=\frac{1}{2}\left(F_{w s}+I_{w s}\right) \quad \mathrm{F}_{w s}, \quad \mathrm{I}_{\mathrm{ws}} \in(1-5)
$$

If $F_{w s}$ is the scaled percent of $C S A G$-S funds per WS, $I_{w s}$ is the scaled per cent unique parts per WS and $N$ is the total WSs.

Then:

$$
\text { Disposal }=1-\left(\frac{Y_{w s}}{Y_{w s M a x}+1}\right)
$$



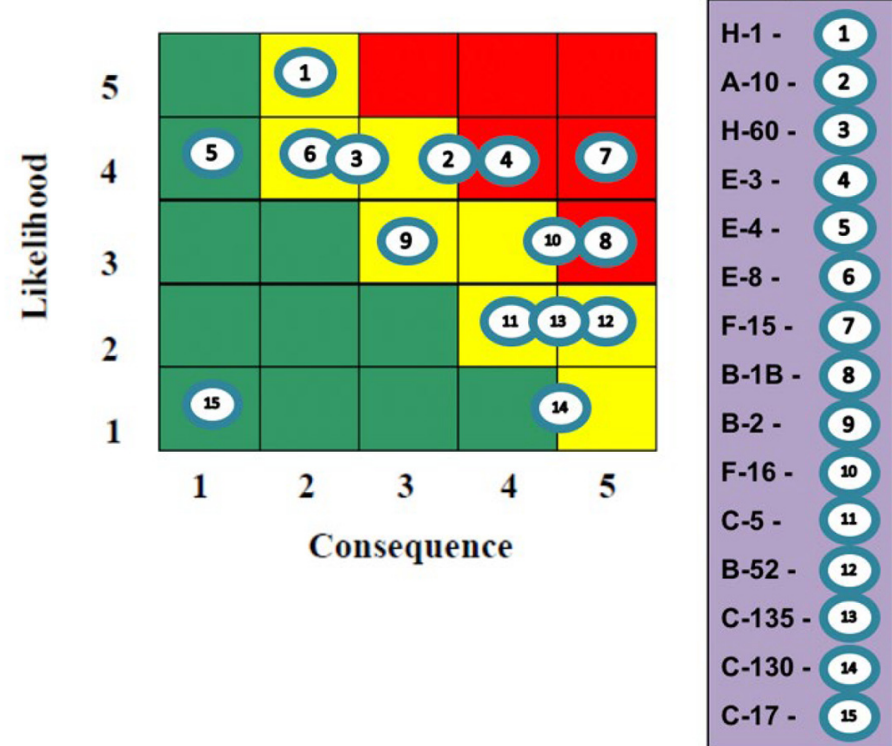

Supply chain risk management

Figure 10. Possible organic supply chain risk matrix

\section{Organic Supply Chain Risk}

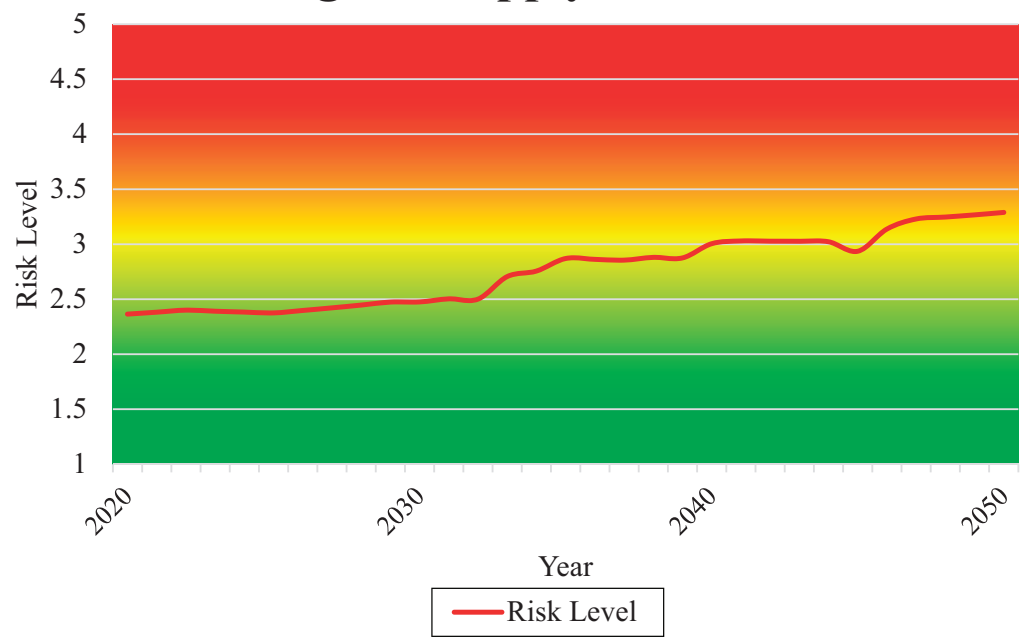

Figure 11. Possible risk representation

If $Y_{w s}$ is years to retirement per WS and $Y_{w s M a x}$ is years to last-managed WS retirement.

Organic supply chain risk as the average of WS risk could be calculated as:

$$
\text { Organic Supply Chain Risk }=\frac{1}{N} \sum_{i=1}^{N=\# w s} \text { WS Risk }
$$




\section{JDAL 4,1}

Figure 12.

Possible organic supply chain risk management reporting and evaluation
This representation could also be overlaid with other decision-making factors in a format for reporting and evaluation (possible format shown in Figure 12).

\section{Organizational strategy and objectives}

This study fills gaps in the literature and provides research and leadership implications. Contingency theory (Lawrence and Lorsch, 1967; Donaldson, 2001) is used to assess the unique capabilities of the organic supply chain established under RBV theory (Wernerfelt, 1984; Barney, 1991) aside from the organizational strategy and objectives of the DoD and USAF in an effort to evaluate the holistic risk to outsourcing decisions and their long-term impact on supply chain viability.

The service branches of the US Armed Forces develop their strategy and organizational objectives based on the DoD's national defense strategy (NDS), which supports the national security strategy (NSS) published by the US President (POTUS). According to the NSS (POTUS, 2017):

A healthy defense industrial base is a critical element of US power and the National Security Innovation Base. The ability of the military to surge in response to an emergency depends on our Nation's ability to produce needed parts and systems, healthy and secure supply chains, and a skilled US workforce [...].

"Support for a vibrant domestic manufacturing sector, a solid defense industrial base, and resilient supply chains is a national priority." The NSS continues by stating:

We will evaluate the strengths and weaknesses of our defense industrial base, including the identification of materials essential to national security, contingencies that could affect supply chains, and technologies that are likely to be critical for the future.

The DoD's unclassified NDS (SECDEF, 2018) prioritizes the building of a more lethal force through the modernization of key capabilities such as building "resilient and agile logistics." It states:

Risk with CSAG-S over Disposal

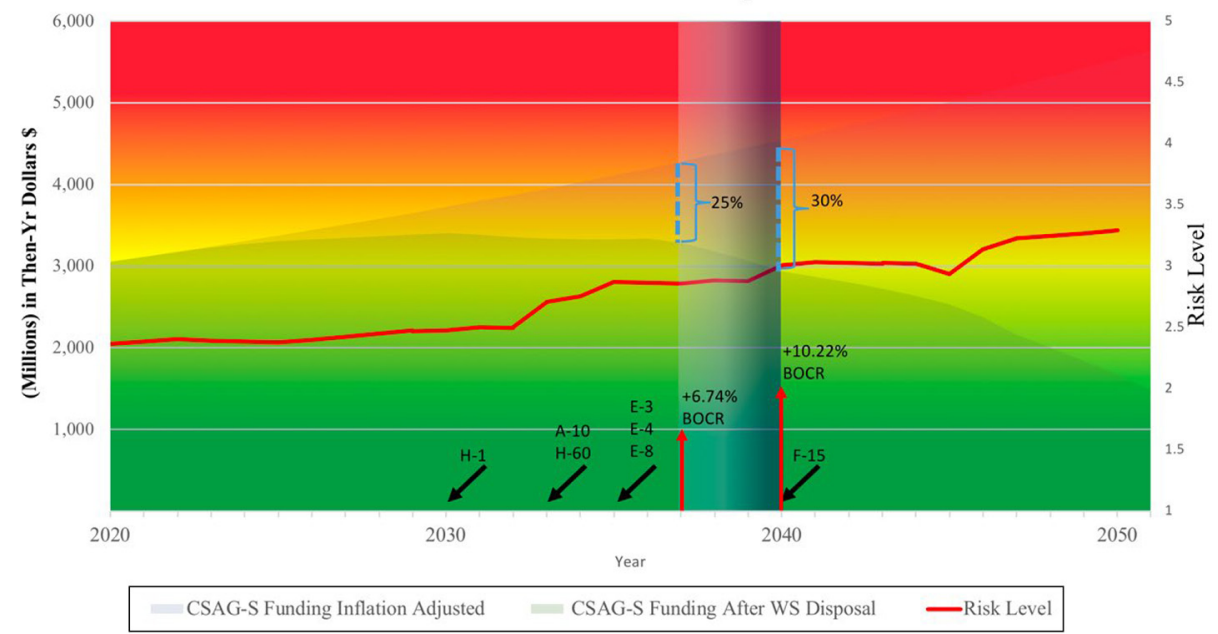


Investments will prioritize prepositioned forward stocks and munitions, strategic mobility assets, partner and allied support, as well as non-commercially dependent distributed logistics and maintenance to ensure logistics sustainment while under persistent multi-domain attack.

Additional key capabilities include "cultivating workforce talent," stating:

Supply chain risk management

Recruiting, developing, and retaining a high-quality military and civilian workforce is essential for warfighting success. Cultivating a lethal, agile force requires more than just new technologies and posture changes; it depends on the ability of our warfighters and the Department workforce to integrate new capabilities, adapt warfighting approaches, and change business practices to achieve mission success. The creativity and talent of the American warfighter is our greatest enduring strength, and one we do not take for granted.

The Air Force Materiel Command (AFMC) strategic plan (AFMC, 2017) sets objectives to "develop an overarching human capital strategy to develop, shape, and size the future workforce to optimize support for both aging and advanced weapon systems and installations [...]" Further elaborating:

Over the next five years and beyond, we will be faced with the task of simultaneously bringing on the newest, most advanced combat systems in the world while maintaining and sustaining an increasingly aging fleet. We need to ensure we have the right capacity and skill mix to handle both these challenges across the spectrum of AFMC activities from acquisition and test to sustainment and logistics. We need to assess our future state workforce needs against current skill mix and size to identify where AFMC has critical areas and deficits. We will develop the strategy, including the necessary training and development plan, as well as the identification of and plan to eliminate roadblocks that would impede our progress getting to the future workforce.

Additionally, AFMC sets objectives to "develop and deploy integrated logistics command and control (LOG C2) to enhance joint/AF operations and readiness." Elaborating further that this is:

To improve readiness and optimize resource allocations, AFMC must operate holistically, taking a strategic, enterprise approach to the Logistics Command and Control (C2) architecture, integrated supply chain. The approach helps to identify the highest priorities and ensure resources are employed in a strategic manner.

The HAF A4 enterprise flight plan (HAF/A4, 2017) lists LOG C2 and a "responsive and resilient supply chain" amongst its A4 enterprise capabilities. It defines a responsive and resilient supply chain as one that "will provide affordable, quality, timely materiel support from point of origin - inventory, maintenance, manufacture or procurement - to point of need enabling the full spectrum of operations in uncontested and contested environments." Further, it is one that can "fully integrate new weapon systems into supply chain processes and systems [...]" "accelerate insertion of new technologies into supply chain processes and systems [...]" "utilize an enterprise view of the supply chain within and across Air Force." Further, it is a supply chain that can "identify, assess and mitigate risk from potential supply chain vulnerabilities" and "utilize an enterprise view of the supply chain within and across Air Force logistics operations to optimize resources to demands."

The Air Force Sustainment Center (AFSC) strategic plan (AFSC, 2019a) defines an objective of "delivering supply chain readiness to enable combat power." Further stating:

AFSC supply chain processes directly support weapon system availability and impact our mission to provide support to the warfighter and maintain readiness across the Air Force and our international partners. 
$\underset{4,1}{\mathrm{JDAL}}$

34

The organizational strategies and objectives of the US Government, DoD and the USAF as they relate to the unique capabilities of the USAF's organic supply chain, stand on their merit. Through the employment of contingency theory, they are useful in assessment besides the RBV framework to evaluate the holistic risk to outsourcing decisions and their long-term impact on supply chain viability. This assessment validates that ensuring the integral viability of the USAF organic supply chain "fits" the contingencies (Donaldson, 2001) and organizational structural design of the USAF, DoD and US national interest.

\section{Discussion and leadership implications}

\section{Core capabilities}

Product support plans under CLS can reduce LOG C2 visibility into component availability and limit military leaders' ability to calculate the risk of surging during a contingency. Figure 13 outlines a hypothetical scenario of logistics command and control complicated through the reliance of CLS contractors brought-on by a lack of a single supply chain manager creating gaps in asset visibility (Mercurio, 2016) (Figure 13).

The AF does not currently have visibility into parts availability at the wholesale level for some CLS WSs. Today, the AF needs contractor permission to redistribute contractormanaged spares in the area of responsibility for some WS fleets. "Without a single supply chain manager, the AF cannot fully achieve logistics multi-domain command and control (Mercurio, 2016)." One study on military logistics (Peltz et al., 2012) discusses how the US Army, following the US entry into operation Iraqi freedom, incurred high costs and costs to readiness by making functionally isolated decisions to shift transportation modes between airlift and sealift. The effects of which propagated across the supply network. Through:

Focusing on the need to reduce airlift, some planners automatically diverted a number of critical readiness items to sealift, without ensuring associated improvements in theater inventory. This was done in part due to misunderstanding, but it is also possible that those in control of planning transportation were overly focused on finding ways to cut transportation costs without carefully considering the broader supply chain implications of their actions (Peltz et al., 2012).

In response to hostilities against a US Allied country by a near-peer adversary, the USAF deployed F-35s, F-22s, C-17s, KC-46s, and B-1s into a contested AOR.

However, the lack of a single supply chain manager to provide the status and location of all spares and support equipment created theater-wide $\mathrm{Log} C 2$ and TAV gaps.

As a result, Logistics leaders are challenged with making timely, informed, and authoritative decisions on spares availability, distribution, and prioritization of the flow of critical assets in and out of theater to meet warfighter requirements.

Figure 13. The JFACC A4's Log C2 problem operational vignette

$\underline{3}$ Sources of Supply

1 Commander

$\underline{5}$ Field Units

$\underline{2}$ Supply Systems

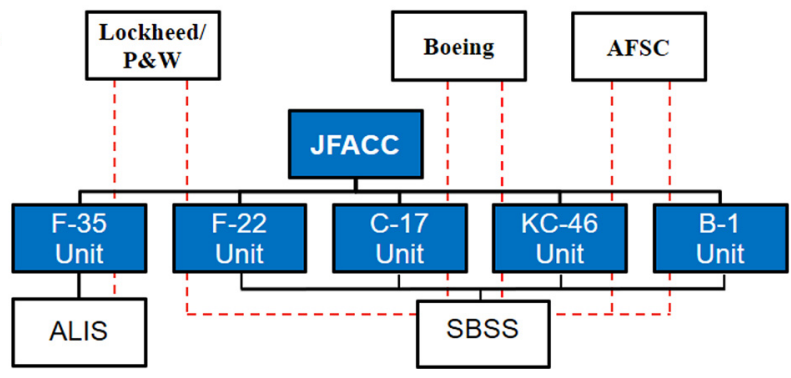


Outsourcing can have a "centrifugal effect" on diminishing military capabilities, potentially making it irreversibly difficult to reconstitute the lost skills, processes and in-place systems (Verkuil, 2007). In one study on the US Army's use of contractors on the battlefield, the Army lost the ability to reconstitute services when the need arose (Camm and Greenfield, 2005):

Over the long run, once the Army gives up a capability, the start-up costs may simply become too high to justify bringing it back in-house, even if it should never have left in the first place. In the short run, if the Army suddenly discovers in a particular contingency that no contract source is available, it does not have the time to reconstitute the capability in-house, regardless of the cost.
Supply chain risk management

\section{Core competencies}

The Gansler Report of 2007 provides a useful extreme example as to the effects of allowing core military competencies to atrophy or never developing them in the first place (Gansler et al., 2007). The context in this example is that of US Army contingency contracting and procurement, but the same principle is germane. Written by the independent commission on army acquisition and program management in expeditionary operations to address a crisis wherein, poor oversight, training and career development of contracting and procurement personnel and incremental and unpredictable funding practices. This resulted in poorly resourced and understaffed contracting corps, which led to severe gaps in capabilities and egregious opportunistic fraud.

Identifying, cultivating and leveraging the core competencies of an organization is a difficult task that is further complicated through decentralization, for which organizational leaders must assume responsibility. "Costs of losing a core competence can be only partly calculated in advance. The baby may be thrown out with the bathwater in divestment decisions (Prahalad and Hamal, 1990).”

\section{Leadership implications}

Currently, there is no defined threshold for the logistics capabilities of the organic supply chain. The results of this analysis, in terms of RBV, suggest that the unique capabilities of the organic supply chain and the core competencies of its workforce will be adversely affected as WSs retire without new workloads to replace them. The USAF could reevaluate product support acquisition policy and processes looking for opportunities to incentivize behavior toward congruence with organizational strategy and objectives (Quinn, 1999) and address concerns over logistics reassignment policy-aligning upstream decisions with downstream impact.

The USAF could "establish an organic baseline supply chain that is flexible and transparent enough to accommodate industry and service partners in a way that creates a win-win situation (Mercurio, 2016)." To enhance supply chain resiliency, the USAF could adopt a multi-objective or multi-criteria assessment for outsourcing decisions, including sustainment objectives. It could adopt an assessment of enterprise risks into its SCM determinization process addressing long-term operations sustainment needs under an RBV framework, including its core competencies, LOG C2, etc. The USAF could do this by using an RBV and Systems framework approach to supply chain resilience as proposed by Blackhurst et al. (2011). 


\section{JDAL 4,1}

\section{Limitations and directions for future research}

A comparative assessment between CLS and organic supply chain RBV factors would help determine the total costs of outsourcing decisions. However, there are significant differences between CLS and organic supply chain cost accounting for the services and personnel who manage the supply chain (e.g. item managers, logisticians and engineers). Within CLS programs, contract line items report material and personnel costs separately, whereas, in the organic supply chain, the cost of personnel is part of the surcharge added to costs of consumables and DLRs under BOCR. Further, cost accounting is also not standardized between CLS providers. Collecting this data will predictably be costly to the government as CLS contractors will charge for the information as their reporting of costs could potentially lead to a government negotiating advantage if the government were able to calculate the contractor's profit (Botio et al., 2009). One potential measurement to assess the true cost of WS retirement or outsourcing is its impact on the BOCR. An estimate of the 20-year consequence suggests that the BOCR surcharge will increase by a rate of $10.22 \%$ as the CSAG-S buy repair budget denominator diminishes with WS disposal. Within the scope of this research, applying RBV factors longitudinally over WS retirement dates, the causality and consequence of SCM outsourcing and WS retirement can be deduced a priori.

There are limitations to using programmed retirement dates in this assessment. Retirement dates at acquisition or later during sustainment are very often improbable. One solution considered using triangulation methods (Jick, 1979) to determine greater accuracy to the dates but concluded that these dates are established as a collective effort between key USAF and DoD decision-makers, and therefore, this method would not increase reliability. Further, risk assessment using the programed date has significant value to resilience from internal or external system disruption. Though there is research into predicting the total cost of WS disposal (Kaye et al., 2015), further research could be conducted to measure the accuracy of disposal dates, though this is outside of the scope of this single paper.

Further research could be conducted into the core competencies of the organic supply chain and how they correspond to its performance (Craighead et al., 2009) and resilience (Sheffi and Rice, 2005). Increasing knowledge management and integration could result in increased performance in logistics operations and contribute to improved LOG C2 (Fugate et al., 2009). Through this understanding, the USAF could maintain preeminence and competitive edge through a core competency strategy approach to future strategic outsourcing (Quinn and Himler, 1994).

\section{References}

AFMC (2017), "Air force materiel command strategic plan".

AFSC (2018), "Air force sustainment Center-Supply pricing”.

AFSC (2019a), "Air force sustainment center strategic plan”.

AFSC (2019b), "Air force sustainment center performance review (supply support Review - SSR) asset availability dashboard chart".

Aven, T. (2008), Risk Analysis, Assessing Uncertainties Beyond Expected Values and Probabilities, John Wiley and Sons.

Barker, T.J. (2011), "A multicriteria decision making model for reverse logistics using analytical hierarchy process”, Omega, Vol. 39 No. 5, pp. 558-573.

Barney, J. (1991), "Firm resources and sustained competitive advantage", Journal of Management, Vol. 17 No. 1, pp. 99-121. 
Becker, G.S. (1964), Human Capital, New York, NY: Columbia.

Blackhurst, J., Dunn, K.S. and Craighead, C. (2011), “An empirically derived framework of global supply resiliency”, Journal of Business Logistics, Vol. 32 No. 4, pp. 374-391.

Boone, C.A., Craighead, C.W., Hannah, J.B. and Nair, A. (2013), "Implementation of a system approach for enhanced supply chain continuity and resiliency: a longitudinal study", Journal of Business Logistics, Vol. 34 No. 3, pp. 222-235.

Borade, A.B., Kannan, G. and Bansod, S.V. (2013), "Analytical hierarchy process-based framework for VMI adoption”, International Journal of Production Research, Vol. 51 No. 4.

Botio, M., Cook, C.R. and Graser, J.C. (2009), Contractor Logistics Support in the US Air Force, RAND Corporation, Santa Monica, CA.

Byrd, T.A., Pitts, J.P. and Adrian, A.M. (2008), "Examination of a path model relating information technology infrastructure with firm performance", Journal of Business Logistics, Vol. 29 No. 2, pp. 161-187.

Camm, F. and Greenfield, V.A. (2005), "How should the army use contractors on the battlefield?", Assessing Comparative Risk in Sourcing Decisions, RAND Corporation, Santa Monica, CA.

COSO (2004), Enterprise Risk Management-Integrated Framework, Committee of Sponsoring Organizations of the Treadway Commission.

Craighead, C.W., Blackhurst, J. and Rungtusanatham, M.J. (2007), "The severity of supply chain disruptions: Design characteristics and mitigation capabilities", Decision Science, Vol. 38 No. 1.

Craighead, C.W., Hult, G.T. and Ketchen, D.J. (2009), "The effects of innovation - cost strategy, knowledge, and action in the supply chain on firm performance", Journal of Operations Management, Vol. 27 No. 5, pp. 405-421.

Da Cruz, R.P., Ferreire, J.J. and Azevedo, S.G. (2013), "Logistics resources in seaport performance: multicriteria analysis", Maritime Policy and Management, Vol. 40 No. 6, pp. 588-613.

Da Silva, A., Tate, W.L. and Pereira, C. (2016), "The contribution of purchasing/supply management to supply chain resilience: insights about an emerging market", POMS 27th Annual Conference, Orlando, 6-9 May.

Dittmann, P. (2014), "UT risk mitigation study shows companies lacking in assessments, strategies", available at: https://utcbanews.wordpress.com/2014/07/17/ut-risk-mitigation-study-shows-companieslacking-in-assessments-strategies/ (accessed 14 May 2019).

Dittman, J.P. and Vitasek, K. (2016), "Selecting and managing a third party logistics provider best practices", Global Supply Chain Institute, available at: https://haslam.utk.edu/sites/default/files/ Kenco.pdf (accessed 11 March 2020).

DoD (1998), DoD Integrated Product and Process Development Handbook, Office of the Under Secretary of Defense for Acquisition and Technology.

DoD (2017), Risk, Issue, and Opportunity Management Guide for Defense Acquisition Programs, Office of the Deputy Assistant Secretary of Defense for Systems Engineering.

Donaldson, L. (2001), The Contingency Theory of Organizations, Safe, Appendices.

El Khayyam, Y. and Herrou, B. (2016), "Analytical hierarchy process based frame-work for supply chain risk management”, International Journal of Scientific and Engineering Research, Vol. 7 No. 7, pp. 1167-1172.

Ellram, L.M. (1996), "The use of the case study method in logistics research", Journal of Business Logistics, Vol. 28 No. 1, pp. 93-137.

Esper, T.L., Fugate, B.S. and Davis - Sramek, B. (2007), "Logistics learning capability: sustaining the competitive advantage gained through logistics leverage”, Journal of Business Logistics, Vol. 28 No. 2, pp. $57-81$.

Fine, C.H. (2000), "Clockspeed-based strategies for supply chain design”, Production and Operations Management, Vol. 9 No. 3, pp. 213-221. 


\section{JDAL 4,1}

Flynn, B.B., Huo, B. and Zhao, X. (2010), "The impact of supply chain integration on performance: a contingency and configuration approach", Journal of Operations Management, Vol. 28 No. 1, pp. 58-71.

Fugate, B.S., Stank, T.P. and Mentzer, J.T. (2009), "Linking improved knowledge management to operational and organizational performance", Journal of Operations Management, Vol. 27 No. 3, pp. 247-264.

Gansler, J.S. Berteau, D.J. Maddox, D.M. Oliver, D.R. Salomon, L.E. and Singley, G.T. III, (2007), "Urgent reform required: army expeditionary contracting report of the "commission on army acquisition and program management in expeditionary operations", available at: www.acq.osd.mil/dpap/ contingency/reports/docs/gansler_commission_report_final_report_20071031.pdf (accessed 11 March 2020).

GAO (2017), Gao-17-744R Weapon Systems Management: Product Support Managers' Perspectives on Factors Critical to Influencing Sustainment-Related Decisions, US Government Accountability Office.

HAF/A4 (2017), A4 Enterprise Flight Plan, US Air Force.

Hartman, P.A. (2013), "The outsourcing-to-Insourcing relocation shift: a response of US Manufacturers to the outsourcing paradigm", $\mathrm{PhD}$ Dissertation, Air Force Institute of Technology, WrightPatterson AFB, OH.

Hätönen, J. and Eriksson, T. (2009), "30+ Years of research and practice of outsourcing - exploring the past and anticipating the future", Journal of International Management, Vol. 15 No. 2, pp. $105-110$.

Heckmann, I., Comes, T. and Nickel, S. (2015), "A critical review on supply chain risk _ definition, measure and modeling”, Omega, Vol. 52, pp. 119-132.

Humphries, A.S. (2003), "Sustained monopolistic business relationships: a UK defense procurement case", PhD Dissertation, Cranfield University, Cranfield.

Jick, T.D. (1979), "Mixing qualitative and quantitative methods: triangulation in action", Administrative Science Quarterly, Vol. 24 No. 4, pp. 602-611.

Kaye, M.F., Harmon, B.R., Gallo, A.O. and MacCarthy, J.E. (2015), Predicting Disposal Costs for United States Air Force Aircraft (Presentation), Institute for Defense Analysis.

Khan, S.A. (2018), A Knowledge Base System for Overall Supply Chain Performance Evaluation: A Multi-Criteria Decision-Making Approach, The University of Quebec.

Kouvelis, P. and Milner, J.M. (2002), "Supply chain capacity and outsourcing decisions: the dynamic interplay of demand and supply uncertainty", IIE Transactions, Vol. 34 No. 8, pp. 717-728.

Kraljic, P. (1983), "Purchasing must become supply management", Harvard Business Review, Vol. 61 No. 5, pp. 109-117.

Lawrence, P. and Lorsch, J. (1967), Organization and Environment, Cambridge, MA: Harvard University Press.

Loredo, E.N., Raffensperger, J.F. and Moore, N.Y. (2015), Measuring and Managing Army Supply Chain Risk: A Quantitative Approach by Item Number and Commercial Entity Code, RAND Corporation, Santa Monica, CA.

Mandal, S. (2012), "An empirical investigation in demand side risk", Romanian Journal of Marketing, Vol. 4, pp. 33-49.

Manuj, I. and Mentzer, J. (2008), "Global supply chain risk management”, Journal of Business Logistics, Vol. 29 No. 1, pp. 133-155.

Mentzer, J.T., Min, S. and Bobbitt, L.M. (2004), "Toward a unified theory of logistics", International Journal of Physical Distribution and Logistics Management, Vol. 34 No. 8, pp. 606-627.

Mercurio, J. (2016), "The future of the organic supply chain, [white paper]", Accessed from 448 SCMW database. 
Meridith, J. (1998), “Building operations management theory through case and field research”, Journal of Operations Management, Vol. 16, pp. 441-454.

Moktadir, M.A., Kumar Mangla, S., Sharmy, T., Luthra, S., Mishra, N. and Garza-Reyes, J.A. (2018), "Decision modeling for evaluating risk in pharmaceutical supply chains", Industrial Management and Data Systems, Vol. 118 No. 7, pp. 1388-1412.

Moore, N.Y., Loredo, E.N., Cox, A.G. and Grammich, C.A. (2015), Identifying and Managing Acquisition and Sustainment Supply Chain Risks, RAND Corporation, Santa Monica, CA.

Olson, D.L. (2012), Supply Chain Risk Management: Tools for Analysis, Business Expert Press, New York, NY.

Peltz, E., Robbins, M. and McGovern, G. (2012), Integrating the Department of Defense Supply Chain, RAND Corporation, Santa Monica, CA.

PMI (2018), Project Management Institute Guide to the Project Management Body of Knowledge, 6th ed., Project Management Inst., Project Management Institute, Newtown Square, PA.

POTUS (2017), "National security strategy of the United States of America", available at: www.whitehouse. gov/wp-content/uploads/2017/12/NSS-Final-12-18-2017-0905.pdf (accessed 11 March 2020).

Prahalad, C.K. and Hamal, G. (1990), "The core competence of the corporation", Harvard Business Review, Vol. 90 No. 3, pp. 79-93.

Prentice, B. and Costanza, D. (2019), MRO Survey 2019, Bigger, Stronger, Faster: The Challenges of a More Global and Digital MRO Market, Oliver Wyman.

Quinn, J.B. (1999), "Strategic outsourcing: leveraging knowledge capabilities", MIT Sloan Management Review, Vol. 40 No. 4, pp. 9-21.

Quinn, J.B. and Himler, F.G. (1994), "Strategic outsourcing", MIT Sloan Management Review, Vol. 35 No. Summer, pp. 43-55.

SAF/FM (2018), "Financial management and Comptroller - UNITED States AIR FORCE WORKING Capital FUND - Fiscal year (FY) 2019 budget estimates February 2018”, Available at: www. saffm.hq.af.mil/Portals/84/documents/FY19/Air\%20Force\%20Working \%20Capital\%20Fund \% 20FY19.pdf?ver=2018-02-12-190958-883.

SAF/FMCE (2019), USAF Raw Inflation Indices, US Air Force.

SECDEF (2018), "Summary of the 2018 national defense strategy of the United States of America", available at: https://dod.defense.gov/Portals/1/Documents/pubs/2018-National-Defense-StrategySummary.pdf (accessed 11 March 2020).

Sheffi, Y. and Rice, J.B. (2005), "A supply chain view of the resilient enterprise", MIT Sloan Management Review, Vol. 47 No. 1, pp. 41-48.

Stierlitz, S.F. (1974), "Depot plant modernization. Air force logistics command, Wright-Patterson AFB, $\mathrm{OH}$ ", Accesed from Air Force Materiel Command Historian database.

Tomer, J.F. (1987), Organizational Capital: The Path to Higher Productivity and Well-Being, New York, NY: Praeger.

Tribble, S. (2019), "U.S. Air force wants to take back sustainment from industry", MRO Network | Aviation Week, 3 April.

USAF (2019), myPers Standard Core Personel Document Library, [Online], available at: https://mypers. af.mil/app/answers/detail/a_id/21602 (accessed 2019).

Verkuil, P.R. (2007), Outsourcing Sovereignty: Why Privatization of Government Functions Threatens Democracy and What We Can Do About It, Cambridge University Press.

Wang, C.N., Huang, Y.F., Cheng, I.F. and Nguyen, V.T. (2018), "A multi-criteria decision-making $(\mathrm{MCDM})$ approach using hybrid SCOR metrics, AHP, and TOPSIS for supplier evaluation and selection in the gas and oil industry", Processes, Vol. 6 No. 12, p. 252.

Washburn, F. (2016), "What is the future of the air force supply chain?", Exceptional Release Military Journal, Vol. 137 No. Spring, pp. 9-28. 
JDAL

4,1

Wernerfelt, B. (1984), “A Resource-based view of the firm”, Strategic Management Journal, Vol. 5 No. 2, pp. 171-180.

Williamson, O.E. (1975), Markets and Hierarchies: Analysis and Antitrust Implications, Free Press, New York, NY.

Yin, R.K. (1994), Case Study Research: Design and Methods, 2nd ed. Sage, Newbury Park, CA.

\section{Corresponding author}

David Loska can be contacted at: David.loska.1@us.af.mil

For instructions on how to order reprints of this article, please visit our website: www.emeraldgrouppublishing.com/licensing/reprints.htm

Or contact us for further details: permissions@emeraldinsight.com 